\title{
AN OPEN INNOVATION AND ITS ROLE IN GLOBAL FISH AND SEAFOOD VALUE CHAINS: BEYOND THE CONVENTIONAL WISDOM
}

\author{
D. A. M. De Silva ${ }^{1}$ and Trond Bjondal ${ }^{2}$
}

\begin{abstract}
Fish and seafood is one of the fastest growing segments in the food market. Value chain management aims at linking, assisting and guiding different actors along the value chain, such as fishermen (producers), processors and retailers up to the final consumer, to capture the best value at all stages of production, processing, marketing and consumption while at the same time observing a sustainable use of fishery resources. Open innovation depends on the external environment and bring ideas and solutions into the company. The current research aims at highlighting the relevance of open innovation for global fishery value chains, especially possibilities for value chain actors to participate in innovation processes and explore possible co-innovation avenues. The present study identifies potential open innovation avenues.
\end{abstract}

Keywords: open innovation, value chain, fish and seafood

\section{INTRODUCTION}

In a dynamic business environment, with complexity of products, rising development costs as well as continuous technological change, companies have to innovate to survive (Trott, 2008). Innovation and food manufacturing always go hand in hand and the innovative capacity of the food manufacturers places them in different positions in the market. Food industry innovation strategies need to be based on the total technology in the food system. Thus, it must be concerned not only with technological changes but also with social and environmental changes, so as to produce food that satisfies the nutritional, personal and social needs and wants of all communities (Earle, 1997).

In the closed innovation model, companies were vertically integrated and resource strength and innovative capacity decided the company's success. Every step of the development of a new product was done inhouse and the company would conceive, design, manufacture and deliver the product as well as support its customers (Duke, 2004). The economic interdependence between countries has significantly increased due to the spread of global value chains. Production has become increasingly fragmented and goods and services are produced in sub sequential stages across different countries (OECD, 2010). Global value chains, especially for food products, directly impact the competitiveness of countries and result in different specialisation patterns. For example, Japan, the world's biggest seafood producer during the $20^{\text {th }}$ century also became the biggest consumer and its neighbours, Thailand and China, became giant processors.

Business in the $21^{\text {st }}$ century will not be the same as in $20^{\text {th }}$ century and networks propelled by the internet and information technology are becoming the basis of economic activity and progress (Chen, 2010). Moreover, the useful knowledge is becoming widespread across 
the organisations, the costs of technology development are rising and product life cycles are becoming shorter. The combination of rising development costs and shortening market windows reduce the investment returns on the innovation investment (Chen, 2010). Open innovation brings novel ideas that organisations must enhance their value creating potential to survive in the competitive business world by using their absorptive capacity and tapping external resources.

The principal aim of this research paper is to explore the existing research on open innovation in the food industry and its relevance to global fishery value chains and developing country participants. Moreover, the paper aims to bridge the gap between open innovation applications in food processing and fish processing and understand the potential applications into new business models of the fish and sea food processing industry. Current research will show the relevance of open innovations for the global fishery value chains, especially potentials and possibilities of value chain actors to participate in innovation processes and explore the possible co-innovation avenues. The open innovation concept is much applied to fast moving consumer goods but little attention has been paid to food manufacturing with minimum attention to fish and seafood. The research aims to propose an agenda for future research on open innovations in global fishery value chains and its impact on sustainability of resource base.

The paper is organised as follows: section one discusses the paradigm shift from closed innovation to open innovation and human capital inputs in the innovation process. Section two is focused on the need of a new business approach to global fishery value chains while section three is devoted to possible ways to promote the open innovation in global fishery value chains. The final two sections discuss the role of open innovation in global fish and seafood value chains and provide a summary.

\section{DISCUSSION}

\section{Open Innovation}

Open innovation deals with an external environment and brings ideas and solutions in to the company from partners, suppliers, wholesalers, retailers, customers and others. Morover, tapping the "wisdom of crowds" through innovation markets has gained favour as a way of creating value (Monitor Company Group Limited Partnership, 2009). Forward looking companies engage with customers, suppliers, employees, "crowds" of independent problem solvers and other parties in collaborative development of products, services or processes. Moreover, the postwestern globalisation changes the face of markets, its products and consumer mind sets.

Open innovation is a paradigm that assumes that firms can and should use external and internal ideas and internal and external paths to market. Open innovation combines internal and external ideas into architecture and systems whose requirements are defined by a business model. The business model utilises both external and internal ideas to create value with internal mechanisms in place to claim some portion of that value (Chesbrough ${ }^{a}$, 2003). A company's value chain no longer exists fully within the company.

Global fishery value chains are composed of actors from different regions, countries and continents. Ideas, people and products flow across company boundaries, to and from other companies, universities and countries. Global fish and seafood value chains directly impact the competitiveness of countries and result in different specialisation patterns across countries. Developing nations holds the lion's share of international fish and seafood trade and global value chains help emerging nations 
in their economic development. The current research aims to investigate the relevance of open innovation into global fish and seafood value chains, its importance to producers and suppliers and sustainability of the resource base. Figure 1 explains the changes of the innovation process over the time, from the closed innovation model into an open innovation model.

Closed innovation capitalises on individual skills and the knowledge of the internal or the research and development team of the company. This implies that in general, human capital inputs are sourced mainly within the firm's boundaries (Romer, 1990). As the opposite to the closed innovation model, open innovation capitalises on the large amounts of external resources available to the firm (Chesbrough ${ }^{\mathrm{b}}$, 2003). Open innovation is about harnessing the in-bound and outbound flows of ideas, technology and skills across a firm's boundaries with the intent of accelerating internal innovation processes and establishing additional, external paths for the commercialisation of their outcomes (Chesbrough ${ }^{\mathrm{b}}$, 2003; Simard and West, 2006).

Fish and seafood value chains are highly scattered, vertically integrated and running across the national boundaries, regions and continents. Much of the production is located in developing countries with raw materials transported to processing giants like China and Thailand. Moreover, value chains end up in high value markets in Europe, Japan or USA. Individuals from different countries join together to supply fish and seafood products to end users. Knowing the fishery value chain, utilising both internal and external resources, is required to develop products. Many of the fish value chains flow through new world economies in Asia and Latin America where education has reached high levels. Rapid industrial development together with high levels of literacy form capable communities that may join the innovation process.

\section{Global fish and seafood value chains: need of a new business approach}

Fish and seafood is among the fastest growing segments in the food market. Key to fish and seafood growth is the buying power in a global perspective (European Commission, 2006). Every year tens of millions of people join the middle and upper classes of societies, demanding more variety and more convenience. This development is evident in many parts of the world and is very noticeable in markets like China, India and Russia (European Commission, 2006). Value chain management in a commercial fishery is a business-oriented approach. Management aims at linking, assisting and guiding different actors along the value chain, such as fishermen (producers), processors and retailers up to the final consumer, to capture the best value at all stages of production, processing, marketing and consumption while at the same time observing a sustainable use of fishery resources.

Fish and seafood value chains are highly dependent on common property resources which are vulnerable due to over-fishing and climate change. Therefore, cooperation among the value chain members on resource utilisation and management is required. High levels of cooperation and partnerships will bring better returns to individual members of the value chain. Value chains for capture and culture fisheries differ from species to species and from country to country, and frequently within regions (De Silva, 2010). Value chains of economically important species, such as tuna, salmon, skipjack, shrimp, tilapia, etc. are composed of several nodes and products that pass through longer chains to meet the consumer (De Silva, 2010). In contrast, some of the species that are not so economically important, but socially important, such as hilsa for Bangladesh, Indian mackerel for Thailand etc., consist of shorter value chains. 


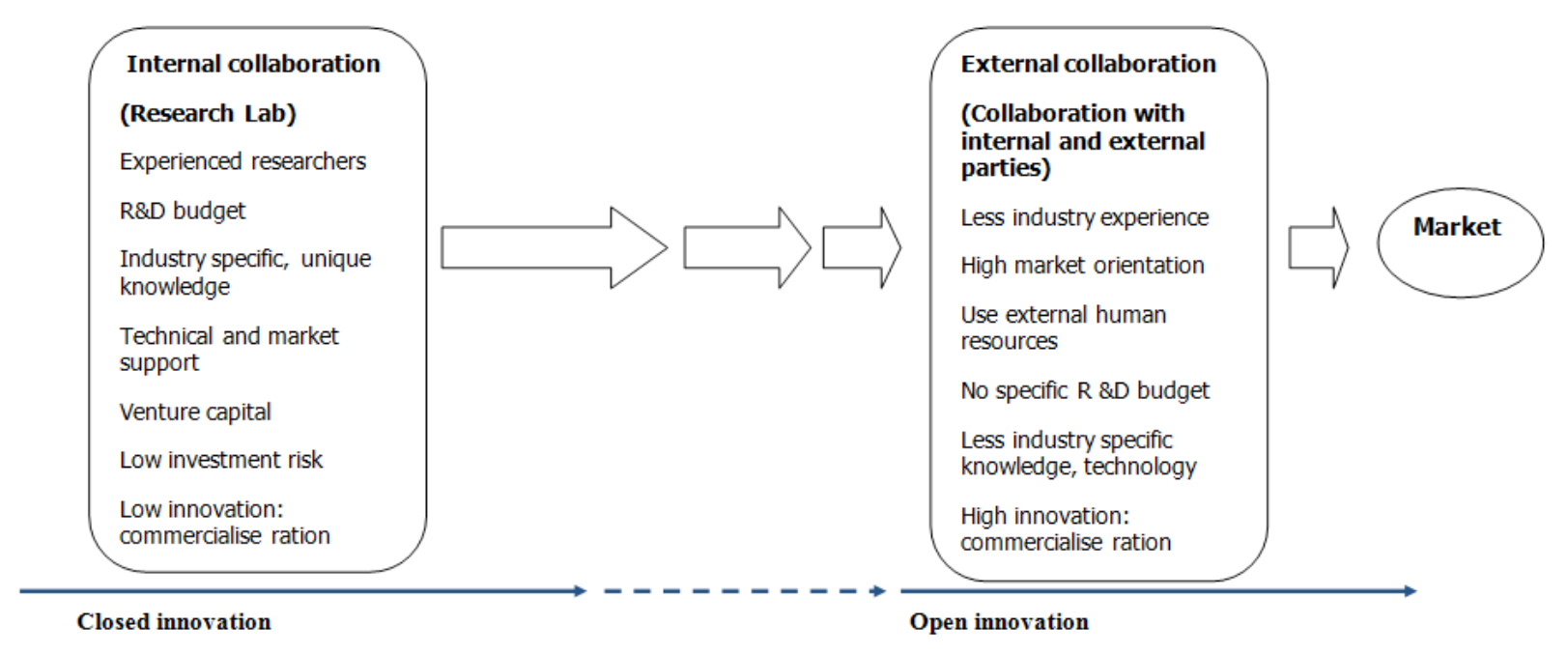

Figure 01: Innovation time line

Source: Authors' research

A value chain describes a model of how fishery businesses receive raw materials as input (captures and culture fisheries), add value to the raw materials through various processes and sell finished products to customers (De Silva, 2010). A value chain is basically composed of two sections, primary activities (production, processing or value addition and trading) and support activities (financing, marketing, human resource management, research and development and administration) (Porter, 1985).

\section{Globalised value chains}

Fish and seafood value chains are today globalised, blurring national boundaries. Developing nations of Asia, Africa and Latin America hold the lion's share of fish and seafood supply to the international market. Traditional technological hubs in Western Europe and North America are weakening their positions as new locations emerge. All value chain members depend on fishery resources and they all need to act collectively to receive an economically viable, feasible, profitable and sustainable resource base. Depleted resources and polluted oceans are threatening to the existence of all stakeholders of the value chain.

\section{High labour costs and aging populations}

The starting nodes of most global fishery value chains are located in developing countries and are simply raw material suppliers with minimum value addition. Most of the value chains end in developed country markets where processing and value addition takes place. Moreover, the majority of the end-users or consumers are located in these developed country markets. This nature facilitates processors to produce products to cater for their own customers.

In the beginning of the $20^{\text {th }}$ century, most of the canneries and processing plants were located in USA, Japan, Norway, Spain and Chile. Industry trends changed drastically during the late part of the $20^{\text {th }}$ century. High production costs, especially labour, changed the direction. Rapid development of information and communication technology as well as infrastructure and low labour costs and close vicinity to resources provide reasons for to locating production facilities in Asia. Most of the production facilities were shifted to China, Thailand, Taiwan, Vietnam, Madagascar, and the Maldives. New locations were set to produce for distinct markets and cater to unfamiliar consumers located in diverse 
regions. Value chain integration, closer ties between members, faster communication and information sharing are essential for catering to ever changing consumer needs. New engines of economic activity and innovation have taken root in the developing world, spawning technologies and talent pools that both supplement and challenge those in the west that were primary drive of economic growth for decades.

\section{Consumer behaviour}

Consumer demand changes rapidly: food habits become globalised, consumers are willing to pay extra for the convenience, and healthy, sustainable, organic, environmentally friendly, certified, anti-biotic free products attract many consumers. Market segmentation is higher than as ever and based on different segmentation strategies. Market segmentation is based on socio-economics, such as gender, ethnicity, religion, education of the consumers as well as geographical areas. Therefore a well connected value chain is essential to cater for the diverse markets.

Fish and seafood consumption in most of the high value markets, such as the EU and USA, is far behind meat. Average annual per capita meat consumption in the EU is about $84 \mathrm{~kg}$ (2009) and showing a slightly increasing trend (European Commission, 2010). The EU has an annual average per capita consumption of fish and seafood of approximately $26.5 \mathrm{~kg}$ (Glitner, 2008). According to the FAO's study on European seafood consumption for the year 2011, there is going to be an overall increase in all commodity groups, except for frozen fish. Prepared/preserved fish will continue to increase in the European market as a result of a change in dining habits and spread of supermarket/retail chains (Glitner, 2008).

Recent trends in the world's biggest seafood market, Japan, are also favourable to meat products. Fish consumption has been steadily declining. Per capita fish-eating fell below that of meat for the first time in 2006 and continued up to 2009 (Yagi, 2011). Average annual per capita fish consumption in Japan lies between 74-75 kg. Changes in life style of Japanese people, busy schedules, working mothers etc., have contributed to the recent decline of fish consumption (Yagi, 2011). Therefore, fish and seafood processors are more concerned with ready to eat fish and seafood preparations or complete meals which appeal to the tastes of today's consumer. China has overtaken Japan's position as top fish and seafood consumer and their consumption pattern would create new market trends. China consumes less high value species such as tuna and salmon than Japan and USA.

\section{Climate change}

Growing recognition of climate change has thrust sustainability to the top of the agenda for every enterprise, imposing environmental costs and regulatory pressure but also creating new opportunities for innovation in conservation and driving down energy costs. Many fish stocks are overexploited (FAO, 2010). Nonetheless, climate fluctuations are also known to cause extensive shifts in species distribution and local biodiversity. Furthermore, climate change and fishing pressures may interact to exacerbate the risk of collapse of fish populations (Brander, 2003).

\section{Stock depletion}

The proportion of marine fish stocks estimated to be underexploited or moderately exploited declined from 40 percent in the mid-1970s to 15 percent in 2008, whereas the proportion of overexploited, depleted or recovering stocks increased from 10 percent in 1974 to 32 percent in 2008 (FAO, 2010). The proportion of fully exploited stocks has remained relatively stable at about 50 percent since the 1970s. In 2008, 15 percent of the stock groups monitored by FAO were estimated to be underexploited (3 percent) or moderately exploited (12 percent) and able to produce more than their 
current catches. Slightly more than half of the stocks (53 percent) were estimated to be fully exploited and, therefore, their current catches are at or close to their maximum sustainable levels, with no room for further expansion (FAO, 2010).

\section{Threat to conventional wisdom: closed innovation}

Most companies are actively seeking to reduce research and development costs during the financial downturn. Especially small and medium size enterprises are facing the burden of R\&D expenditure and are seeking strategic avenues to cut R\&D budgets. Companies are trimming the number of $R \& D$ projects and taking new approaches to R\&D (McKinsey and Company, 2009). Common solutions are shorter-term lower-risk projects focusing on minor changes to existing products.

Reduced research and development budgets and budgetary restrictions may adversely affect the innovation process of the companies. The aggregate EU situation was rather static over the last decade with a similar pattern in the USA (Grablowitz et al., 2007). Increased use of indirect funding instruments such as tax incentives and decrease of government funding serve to suggest a decreasing relevance of direct funding (Grablowitz et al., 2007). Funding for general education and direct support for industrial production and technology are related policy issues which will lead to develop a better external environment (Grablowitz et al., 2007). Moreover, the number of researchers is shrinking in business and manufacturing but increasing in the services sector (Grablowitz et al., 2007).

These are alarming signals to manufacturing firms to re-think their innovation models and outsource the R\&D functions. New concepts, innovating together, shared knowledge and wisdom along the channel will reduce the damage caused by low R\&D budgets. Most of the multi-nationals are facing the problem of less marketable products born with heavy R\&D bills. One good example is Kraft Foods which currently hold $2.2 \%$ of patents on food manufacturing with an internal R\&D team composed of 2,000 scientists, chemists, and engineers (Jusko, 2008). A focus on R\&D and innovation is becoming ever-more critical for production companies in the food service sector to continue to distinguish their product lines from the competition and, equally important, to develop new markets and revenue channels (Sousa, 2008). Open innovation will provide answers to current barriers on innovation in the agri-food sector with its many network and chain links (Fortuin and Omta, 2009).

\section{Possible ways to promote open innovation in value chains}

\section{Open value chain platform}

Creating economic value from intellectual property requires a value chain that links intellectual assets all the way from $R \& D$ to a final product or service in the hands of a customer (Duke, 2004). The potential for open innovation with suppliers and buyers to leverage innovation resources and capabilities is underutilised (Fortuin and Omta, 2009). Moreover, Fortuin and Omta (2009) explained the uneven power distribution in the chain, where especially the high pressure of buyers acts as a strong driver for innovation. Figure 2 illustrates the open flat form or open innovation model for the fish and seafood value chain members. The model was originated from the value chain model of the Porter (1985) where primary value chain activities (production, processing and trading) were combined into the secondary activities (finance, marketing, human resources management, administration and research and development).

The proposed model is designed to create an open flat form for all value chain members and facilitate co-innovation opportunities. The model will help to generate better understanding among members, and closer 
business relationships which finally leads to creation of new business ideas. Cooperate partners will have a chance to cooperate their ideas in a cost effective way. Moreover, all value chain participants have a chance to get together and develop common ideas and this will open up new resource management avenue which was previously ignored in many product development agendas. The open platform facilitates the use of both internal and external resources of its stakeholders and to expand the resource boundaries. Especially the concept of innovate or develop together strengthens the ability of value chain members and helps them to think beyond their boundaries. Innovation in the open flat form provides better chances to meet the expectation of the members of the value chain and market oriented products with less market risk.
Open platforms provide common ground for generating ideas and developing products. Different types of open platforms are currently practised in other industries and the possibilities are good for the fish and seafood industry. Research and development platforms, marketing, design and ideas platforms, collective intelligence and prediction platforms and HR and freelances platforms are some industry examples. Open platforms can supply life blood to the marketing and design programmes. Customer attitudes, values and behaviour are unique to each and every market and collaboration helps to share the ideas and design location specific marketing campaigns.

\begin{tabular}{|c|c|c|c|c|c|c|}
\hline \multicolumn{2}{|c|}{$\begin{array}{l}\text { Production } \\
\text { Fish catch (open } \\
\text { access fisheries/ } \\
\text { aquaculture) }\end{array}$} & $\begin{array}{l}\text { Inbound logistics } \\
\text { Management of } \\
\text { raw material stocks }\end{array}$ & \multicolumn{2}{|c|}{$\begin{array}{l}\text { Processing/add } \\
\text { value } \\
\text { Semi-finished } \\
\text { Finished (ready to } \\
\text { cook/eat) }\end{array}$} & $\begin{array}{l}\text { Outbound logistics } \\
\text { Air freight } \\
\text { Shipping } \\
\text { Distribution } \\
\text { Insurance } \\
\text { Export }\end{array}$ & V \\
\hline $\begin{array}{l}\text { Finance } \\
\text { Financing } \\
\text { (venture } \\
\text { capital) } \\
\begin{array}{l}\text { Investment } \\
\text { planning }\end{array} \\
\text { Manage } \\
\text { relationships }\end{array}$ & $\begin{array}{l}\text { Marketins } \\
\text { Product } \\
\text { Price } \\
\text { Place } \\
\text { Promotion } \\
\text { People } \\
\text { Process } \\
\text { Physical } \\
\text { evidence }\end{array}$ & $\begin{array}{l}\begin{array}{l}\text { Human } \\
\text { Resource }\end{array} \\
\text { Managem } \\
\text { Recruitme } \\
\text { Selection } \\
\text { Training } \\
\text { Compensa } \\
\text { rewards } \\
\text { Transfers }\end{array}$ & on \& & $\begin{array}{l}\text { Administration } \\
\text { Coordination of } \\
\text { factory \& offices } \\
\text { Machinery, } \\
\text { equipments \& } \\
\text { people } \\
\text { ICT services } \\
\text { Supplies } \\
\text { Procurement }\end{array}$ & $\begin{array}{l}\begin{array}{l}\text { Research \& } \\
\text { Development }\end{array} \\
\text { Idea generation } \\
\text { Product design } \\
\text { Product } \\
\text { development }\end{array}$ & $\begin{array}{l}\mathbf{L} \\
\mathbf{U} \\
\mathbf{E}\end{array}$ \\
\hline
\end{tabular}

Figure 02: Open value chain platform

(adapted from Porter, 1985). 


\section{Invite through social networking}

This is the most promising and effective way of connecting together. Social networks play a great role in connecting members across regions and the process is facilitated by the rapid developments of the information communication technology. The technological infrastructure facilitates connection of people across the national boundaries within seconds. While this helps to develop frequent contacts between partners, faster and reliable information sharing is a key to smooth running of the value chains. Strong ties, frequent contacts, sharing of market information and developing ideas together will help to create marketable products with better economic returns.

Figure 3 outlines the all possible stakeholder options for the fish and seafood manufacturer. Wider networks with frequent contact provide better idea sharing and which facilitates the development procedures. Social networks play a great role in catering to large Asian ethnic markets in the West where fish and fishery products with traditional taste are in very high demand. The food service industry based on ethnic cuisine, such as Chinese, Thai and Indian restaurant chains and their customer base represents high demand for authentic flavours and tastes. Wider social networks with strong connections connect producers and consumers in an efficient manner.

\section{Invite through on-line community}

This method is common among most multinational companies where strong information and communication technologies are in use. Companies develop and manage closer and stronger links with their stakeholders and invite them to engage in idea generation. In general, online communities are rewarded based on the quality of their idea. This method is especially important for companies that engage in international markets where catering for distinct customers is needed.

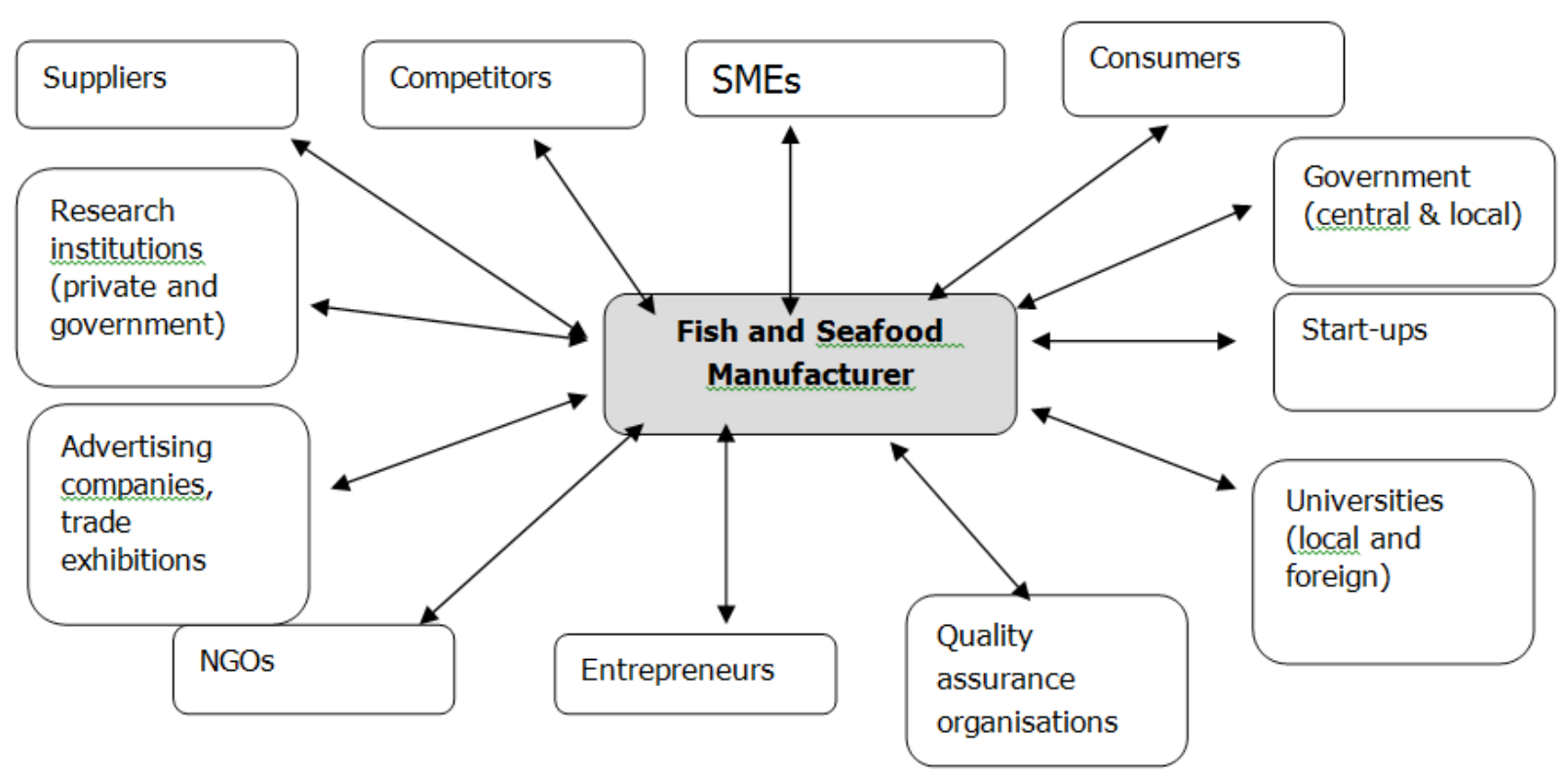

Figure 03: Social network diagram with possible partners of the fish and seafood manufacturer 


\section{Invite through open platform}

Open innovation can help catalyse platform innovation by fostering open partner relationships and transactions (Monitor Company, 2009). iPhone, App Store and Google Maps provide successful endeavours of open partner platforms. Apple's iPhone Apps Store or Google Maps attract diverse partners who find value and contribute to the platform by developing on top of popular products (Monitor Company, 2009). Co-innovation or innovation partnership is one of many models for opening an enterprise, connecting with external parties and extending the innovation process and dialogue to developers and consumers.

Starbucks provides an excellent practical example, where the company invites external parties to submit their novel ideas to Starbucks' special portal, "My Starbuck Idea". In the same site they invite people to vote for the ideas and then select the best ideas and divert funding for the selected ideas to commercialise. Moreover, fish and seafood manufacturers have possibilities to invite their clientele to generate novel fish based meal ideas and through voting have a chance to select the best ideas to commercialise. On the other hand this method provides chances to meet distinct consumer markets and their demands.

\section{Invite through special programmes or external challenges}

Special programmes and events vary from competitions and sponsorships to public relations events. Giant multinational food manufacturers have fruitful experiences of special programmes. Procter and Gamble $(P \& G)$ are the pioneers of this new business model, benefiting from external idea generation. Their model, "Connect and Develop", generates ideas and incubates them within their premises so that they can be commercialised. This model generates a win-win situation to both the company and innovators. Moreover, General Mills, one of the world's largest food manufacturers, has developed a model, called "G-Win" and invites people around the world to join this programme, to innovate and win prizes. They make open invitations through the web, requesting people to submit innovative ideas as solutions to current matters on products or product inventions. General Mills is dedicated to building meaningful and sustainable relationships that will not only benefit the company and its brands, but also its external partners. Partners who help the company achieve its innovation goals can benefit from General Mills' resources (General Mills, 2011).

A similar programme has developed in Kraft Food Inc., whose business model is called "Innovate with Kraft". Kraft has a long history of developing innovative products to meet consumer needs. They certainly have a strong internal innovation capability. However, they also realise there is a very large amount of innovation occurring outside Kraft (Kraft Foods Inc. 2011). Open innovation is about connecting with external innovators to extend innovative capacity and capability (Kraft Foods Inc., 2011).

\section{Open partnerships}

Partnerships allow access to additional talent and reduce the research and development costs. Open innovation is about working with external innovation partners to speed the development of new products as well as reduce the time it takes to bring new products to markets.

Many food manufacturers have used multiple avenues to connect with external partners. Kraft Foods practise multiple avenues for supplier support on their idea generation. Supplier relationship segmentation, innovation potential diagnostic and supplier innovation challenge are utilised to acquire support from 
diverse suppliers and help to identify which suppliers have the potential to help Kraft to bring more innovations to the market.

The economic downturn together with many other financial matters restricts the R\&D budgets of many manufacturers. With this method companies openly invite partners to submit the innovative ideas to address some of their current concerns through the company website. This helps them to generate a pool of new ideas They then select the most appropriate ideas and invite the owners of the $j$ new concepts to develop the products with the company's facilitation. Finally, the most promising products are selected and payment is only for the selected ideas or for their patent rights.

Threadless.com, the online, Chicago-based t-shirt company, was not your typical fashion apparel company (Lakhani and Kanji, 2008). The company turned the fashion business on its head by enabling anyone to submit designs for t-shirts and asking its community of more than 500,000 members to help select winning designs. Threadless encouraged community members to actively participate by critiquing submitted designs, blogging about their daily lives, posting songs and videos inspired by the designs, and, most important, purchasing t-shirts that have won the weekly design competitions (Lakhani and Kanji, 2008).

In general, companies accommodate brokers to scan for innovative products or services that can be licensed to target new opportunities. External organisations handle or facilitate the innovation and external members act as knowledge brokers. Knowledge brokers foster the innovation and management of idea generation towards commercialising the products and promoting international opportunities. Knowledge brokers can play an important role in open innovation processes (Sousa, 2008). They act as catalysts, accelerating the combination of complementary knowledge and skills necessary to solve innovation problems, by making the right connections and links with solvers and seekers (Sousa, 2008). Examples of successful technology broking partnerships include Glaxo Smith Klein and, XETHANOL and UTEK.

Business incubators usually links with partners for open or thematic consortiums to gain technology, market insight and find new opportunities in un-tapped markets for joint research and development ventures. US Advanced Battery and Sustainable Index are two successful examples for this type.

\section{Role of open innovation in global fish and seafood value chains}

Fish and seafood value chains are linked globally and need new business tools to remain competitive in the market place. Today's business environments are dynamic, diverse, and increasingly complex and carry high levels of uncertainties. Especially, fish and seafood products cater to consumers in diverse markets all over the world where producers never meet or rarely meet the final consumers of their products.

An open innovation provides opportunities to value chain members to connect to generate ideas and develop marketable products with low production budgets. Despite being located in a one production destination, relatively distant from most global decision centres, the manufacturer is a catalyst for connections among members of the value chain and their networks. The majority of the producers located in the developing world have paid limited attention has to their own R\&D activities. In general they follow the guidelines or the procedures of their buyers, such as retailers, traders, distributors etc. Non availability or limited availability of venture capital keep them away from own R\&D activities. An open platform developed from the value chain integration will allow them 
to join with others in the value chain and to develop marketable products in cost effective ways. Most importantly, this method will bring better resource management options to producers. An open value chain platform provides opportunities to all stakeholders to join together, generate ideas, manage risks, address sustainability and climate change issues, and develop products which really match with market trends.

Food security, climate change and sustainability are three critical questions that value chain members must face. On the one hand, producers are willing to market their products for a low price. On the other hand, manufacturers are set to develop expensive finished products from cheap raw materials with high amounts of discards. Consumers in most of the producer destinations are poorly fed with low calorie and nutrients intakes while consumers in affluent high markets have to pay premium prices for finished products. As an example, fresh whole Blue fin tuna to the Japanese sashimi market where only selected loins are used as an expensive sashimi treat, while low priced by-products have little or no economic value. The open value chain platform provides better solutions for this type of resource management issue. One good example, Producer destinations themselves produce sashimi loins or Saku blocks and directly export to the retailers in Japan. Technology brokering and closer networks help producer destinations to tap the market with better economic returns on one hand and, on the other hand, consumers benefit from affordable pricing. Moreover, by-products generated from this production process will cater to the demands of the local market or other industries like fish meal producers.

Most of the global fish and seafood value chains end up in the EU, USA and Japanese markets. Special care and attention is needed to cater for these highly regulatory, price conscious markets where co-innovation or innovate together can play a great role.

\section{CONCLUSION}

Fish and seafood markets are growing rapidly with a wide variety of market requirements. Value chains are closely interlinked with disappearing boundaries and catering to multicoloured consumers. On the other hand, the resource status reached alarming levels and the global economic crisis worsened the situation of consumers. Therefore, manufacturers look for cost effective ways to cater for present markets. In general, research and development budgets became a burden to many manufacturers, especially in developing countries. Open innovation provides strategically important solutions for many of the challenges facing manufacturers. Especially during the economic recession, innovation is more than ever the only solution left to generate growth. Crowd sourcing or tapping the external wisdom is more economical than other alternatives. The recession presents a good opportunity to collaborate with others on finding, developing and marketing new ideas (Rae, 2008). Open innovation allows companies to connect with external crowds, to find new ideas, methods, technologies and often co-develop co-branded products. This new way the successful open innovation ventures shares the risks as well as the rewards, opening up win-win situations for all partners. Moreover, developing and marketing products through a collaborative approach or open platforms facilitates better resource management. Innovating, developing and marketing together links producers to consumers which lead to effective utilisation of depleted fishery resources with prospects for improved sustainability. 


\section{REFERENCES}

Brander, K. M. (2003). Climate change and fisheries, ICES/GLOBEC Coordinator, International Council for the Exploration of the Sea, Denmark. pp 14-15.

Cheng, C. (2010). Open innovation to increase innovation performance: evidence from the large scale Chinese firms, The XXI ISPMIM conference - Dynamics of Innovation, Bilbao, Spain.

Chesbrough a , H.W. (2003), “Open Innovation: The New Imperative for Creating and Profiting from Technology”, Harvard Business School Press.

Chesbrough $^{\text {b }}$ H.W. (2003). The era of open innovation, MIT Sloan Management Review, Vol. 44 , pp 35-41.

De Silva, D.A.M. (2010). Value chain of fish and fishery products: origin, functions and application in developed and developing country markets, Value chain project, Food and Agriculture Organisation (FAO), Rome Italy. pp 7-10.

Duke, C.B. (2004). Creating Economic value from research knowledge, The Industrial Physicist, American Institute of Physics pp 29-31.

Earle, M.D. (1997). Innovation in the food industry, Trends in Food Sciences and Technology, Vol.8, pp 166-175.

European Commission, (2006). Fish and seafood industry: consolidation and outsourcing of processing, J.H.M. Wijnands, B.M.J. van der Meulen and K.J. Poppe (Eds.), Competitiveness of the European food industry: An economic and legal assessment, pp123-125.

Food and Agriculture Organisation (FAO), (2010). The state of world fisheries and aquaculture, Food and Agriculture Organization, Rome Italy, pp 35-36.

Fortuin, F.T.J.M. and Omta, S.W.F. (2009). Innovation drivers and barriers in food processing, British Food Journal, Vol.iii, No.8, Emerald Group Publishing Limited. pp 839-851.

Jusko, J., (2008) Kraft crafts an open innovation strategy, www.industryweek.com/articles Accessed 5th November 2011

Lakhani, K.R. and Kanji, Z. (2008). Threadless: The Business of Community. Harvard Business Publishing, http://cb.hbsp.harvard.edu , Accessed 10 $0^{\text {th }}$ November 2011.

General Mills. (2011). General Mills: open innovation will move from one-to-one to many-tomany. www.foodnavigator-usa.com/suppliers2/General-Mills-openinnovation, accessed 12th December 2011

GLITNIR, (2008). EU seafood industry report, GLITNER seafood research, pp3-7.

Grablowitz, A., Delicado A., and. Laget, P. (2007). Business R\&D in Europe: Trends in expenditures, researcher numbers and related policies, European Commission, Joint research centre, Directorate General Research, pp 1-6. 
Kraft Foods Inc., (2011). Why innovate with Kraft?, http://www.kfcollaborationkitchen.com/, accessed 15th December 2011

McKinsay and company, (2009). R\&D in the downturn: McKinsey Global Survey Results, McKinsey Quarterly, www.mckinseyquarterly.com Accessed 3 $3^{\text {rd }}$ November 2011.

Monitor Company Group Limited Partnership. (2009). Taking advantage of tumultuous times, Monitor Company Group Limited Partnership, www.monitor.com Accessed $20^{\text {th }}$ October 2011.

Organisation for Economic Co-operation and Development (OECD), (2010). Global Value chains and emerging economies, Joint OECD/World bank workshop, Paris, www.oecd. org Accessed 23 $3^{\text {rd }}$ October 2011.

Porter, M. E. (1985). Competitive advantage, Free Press, New York.

Romer, P.M. (1990). Endogenous technical change, Journal of political economy, vol. 98, pp 571-582.

Simard, C. and West, J. (2006). Knowledge networks and the geographic locus of innovation in H.W. Chesbrough, W. Vanhaverbeke and J. West (Eds.), Open innovation: Researching a new paradim, Oxford university press, pp 220-240.

Sousa, M. (2008). Open innovation models and the role of knowledge brokers, Sociedade Portuguesa de Inovacao, Portugal, www.ikmagazine.com Accessed 25 $5^{\text {th }}$ October 2011.

Trott, P. (2008). Innovation management and new product development, $4^{\text {th }}$ edition, Prentice Hall, UK.

Yagi, N. (2011). Value chains of fishery products in Japan, Graduate School of Agricultural and Life Sciences, The University of Tokyo, pp 12-13. 